\title{
Aetiology of acute gastroenteritis in infancy and early childhood in southern India
}

\author{
P. P. MAIYA, S. M. PEREIRA, M. MATHAN, P. BHAT, M. J. ALBERT, AND S. J. BAKER \\ From the Departments of Child Health and Pathology, and the Wellcome Research Unit, Christian Medical \\ College Hospital, Vellore, Tamil Nadu, India
}

SUMMARY The aetiology of acute gastroenteritis was studied in 50 infants and young children. Bacterial pathogens were isolated in 33, enteropathogenic E. coli (EPEC), Salmonella, and Shigella being the commonest isolates. Rotaviruses were detected in the stools of 13 of the cases. All children with gastroenteritis in whom rotavirus was detected were seen during the months July to December. In 30 children who served as controls, EPEC were isolated in 6, but rotavirus was detected in none. It is concluded that infection with rotaviruses is a significant cause of morbidity in children with gastroenteritis in southern India.

In the first years of life children in India have an average of 5 to 6 episodes of diarrhoea a year (Kamath et al., 1969). Diarrhoea is more prevalent in infants who are artificially fed, in those of lower socioeconomic status, and in those who are malnourished. The morbidity and mortality of gastrointestinal disease is also greater in malnourished than in well nourished infants (Jadhav, 1965; James, 1972). For these reasons childhood diarrhoea is a major public health problem in developing countries.

In the most carefully conducted studies of acute gastroenteritis in different parts of the world, bacterial pathogens have been isolated in less than $30 \%$ of the children (Prakash et al., 1963; Cramblet and Siewers, 1965; Moffet, et al., 1968; Bhat et al., 1971a). It was therefore assumed that viruses might play some part in the aetiology, but there was no clear-cut evidence to support this until Bishop et al. (1973) detected reovirus-like particles in duodenal biopsies and stools of children with acute gastroenteritis. Preliminary studies in this hospital showed the presence of this virus in the stools of some children with acute enteritis (Holmes et al., 1974). Our study was undertaken in an attempt to determine the relative roles of bacterial and viral agents in the acute diarrhoeas of childhood in southern India.

\section{Materials and methods}

Fifty children with acute gastroenteritis were studied

Received 27 September 1976 from July 1974 to July 1975 . All the children were below 2 years of age and had acute diarrhoea of less than 5 days' duration. Diarrhoea was defined as the passage of 3 or more stools of altered consistency. Infants under 30 days of age, children passing blood and mucus in the stools, and those who had had prior treatment were excluded.

In each case the history and physical examination, including the clinical assessment of the degree of dehydration, were recorded by the same observer (P.P.M.). Children with marked loss of tissue turgor, oliguria, or anuria of 12-24 hours' duration, with evidence of peripheral circulatory failure were classified as severely dehydrated (10\% dehydration), and those with mild loss of tissue turgor, without peripheral circulatory collapse, or oliguria as mildly dehydrated $(5 \%$ dehydration).

Infants with dehydration were treated with standard parental fluid therapy. The fluid deficit was corrected in 6 hours with Hartman-Ringer lactate, $50 \mathrm{ml} / \mathrm{kg}$ and $100 \mathrm{ml} / \mathrm{kg}$, respectively, for children with 5 and $10 \%$ dehydration. Maintenance therapy with $1 / 5$ Hartman-Ringer lactate with $5 \%$ dextrose was given at $100 \mathrm{ml} / \mathrm{kg}$ over the next 18 hours and on subsequent days as necessary. Potassium chloride $0.75 \mathrm{~g}$ was added to each $250 \mathrm{ml}$ of maintenance fluid. When acidotic breathing was present, $4 \mathrm{ml} / \mathrm{kg}$ $8.4 \%$ sodium bicarbonate was also administered. Oral feeding was started within 24-48 hours of admission, with electrolyte solutions and increasing strengths of milk.

Thirty infants and children of the same age and socioeconomic status as the patients were studied as controls, with the informed consent of their 482 
parents. All were in apparent good health, had no gastrointestinal symptoms, and had not received antibiotics.

Standard methods were used for the isolation and identification of bacterial pathogens (Bhat et al., 1974; Bhat and Rajan, 1975). In brief, fresh stool samples were inoculated on the MacConkey agar (MA), desoxycholate citrate agar (DCA), bismuth sulphite agar (BSA), xylose lysine desoxycholate medium (XLD), Salmonella-Shigella agar (SSA), thiosulphate citrate bile salt sucrose agar (TCBS), blood agar (BA), selenite enrichment broth (SF), and peptone water with $3 \%$ sodium chloride (PW). After overnight incubation SF was subcultured on to SSA to look for Yersinia enterocolitica (Asakawa et al., 1973), and PW was subcultured onto TCBS to isolate Vibrio parahaemolyticus (LeClair et al., 1970). All cultures were incubated at $37^{\circ} \mathrm{C}$ aerobically. BA, MA, XLD, and TCBS were examined after overnight incubation and the rest of the plates after overnight as well as after $\mathbf{4 8}$ hours' incubation.

Suspicious-looking colonies from MA, XLD, DCA, SSA, BSA, and TCBS were screened biochemically and when suggestive of Salmonella, Shigella, and Vibrio cholerae were confirmed serologically. 10 serotypes (O111 :B4, O55:B5, O26:B6 O86:B7, O127:B8, O119:B14, O124:B17, O125:B15, $\mathrm{O} 126: \mathrm{B} 16, \mathrm{O} 128: \mathrm{B} 12)$ were used to detect enteropathogenic E. coli (EPEC). From each specimen yielding none of these 10 EPEC, three colonies were held in nutrient agar deeps for serological identification for the presence of other serotypes such as $\mathrm{O} 20, \mathrm{O} 1$, and $\mathrm{O} 153$, which are associated with infantile diarrhoea (Orskov et al., 1971). These cultures were sent to Dr. B. Rowe, Salmonella and Shigella Reference Laboratory, London, for final serological identification.

Stools were initially processed for viruses by the technique of Bishop et al. (1974), treated with trifluorotrichlorethane and a final spin through $45 \%$ sucrose. When 10 specimens had been processed and it was confirmed that both methods gave the same detection rate of rotaviruses, the method was changed to that of Flewett et al. (1974) with the addition of filtration through a $1 \cdot 2 \mu \mathrm{m}$ millipore filter before the final centrifugation. The deposits were negatively stained with molybdate and examined with a Philips EM 200 electron microscope.

\section{Results}

\section{Patients.}

Clinical features. Before the onset of illness 3 patients had been breast fed exclusively, in 26 breast milk was supplemented with milk feeds, and 21 were artificially fed. The majority of the artificially fed infants were receiving a 1:1 milk formula.

On admission 7 were adequately nourished, 32 were under-nourished, 11 were marasmic, and 1 had marasmic kwashiorkor (Lancet, 1970). 32 of the children were seen within 2 days of onset of illness and the remainder within 5 days of onset. On admission all children were passing watery stools; in 6 , subsequent stools contained mucus. 15 children were severely dehydrated and 24 were moderately dehydrated. 14 had metabolic acidosis with a serum bicarbonate $<14 \mathrm{mEq} / \mathrm{l}(<14 \mathrm{mmol} / \mathrm{l})$, and $10 \mathrm{had}$ a serum potassium $<4 \mathrm{mEq} / 1(<4 \mathrm{mmol} / \mathrm{l})$.

Light microscope examination of the stools showed a bacillary exudate in 3 patients. In no case was there evidence of a parasitic cause for the diarrhoea such as amoebiasis, giardiasis, or strongyloidiasis.

Bacteriology. 33 of the 50 patients had one or more bacterial pathogens in their stools (Table). The commonest organisms were EPEC, serotypes O26:B6,

Table Bacterial and viral isolates from stools

\begin{tabular}{llll}
\hline & \multicolumn{2}{l}{ No. of children studied } \\
\cline { 2 - 4 } & $\begin{array}{l}0-6 \mathrm{~m} \\
(n=24)\end{array}$ & $\begin{array}{l}7-12 \mathrm{~m} \\
(n=21)\end{array}$ & $\begin{array}{l}13-24 \mathrm{~m} \\
(n=5)\end{array}$ \\
\hline EPEC & $12 \mathrm{a}, \mathrm{b}$ & $8 \mathrm{c}, \mathrm{d}, \mathrm{e}$ & $5 \mathrm{f}, \mathrm{g}$ \\
Shigella & 2 & - & $1 \mathrm{f}$ \\
Salmonella & 1 & $2 \mathrm{c}$ & $1 \mathrm{f}$ \\
Vibrio eltor & - & $2 \mathrm{~d}$ & - \\
$\begin{array}{l}\text { Providencia* } \\
\text { Pseudomonas }\end{array}$ & 1 & - & - \\
Klebsiella* & 1 & - & - \\
Rotavirus & 1 & - & - \\
\hline
\end{tabular}

* Not usually considered pathogens, see text.

Note: Children with mixed bacterial and viral infections are indicated by letters.

O126:B5, O111:B4, and O128:B12 predominating. It is noteworthy that of the 6 children whose stools contained mucus after admission, 5 had pathogenic bacteria in the stools (Sh. sonnei; EPEC 2; EPEC and Vibrio eltor; EPEC, Salmonella, and Sh. sonnei, respectively). Of the 3 children with bacillary exudate in their stool, Shigella was cultured from 2 and Pseudomonas aeruginosa from 1.

Virology. Electron microscope study of the stools showed rotavirus in the stools of 13 children (Table), all of whom were admitted between July and December 1974. 7 were febrile and 10 moderately or severly dehydrated. However, all recovered within 7 days of the onset of symptoms. 4 children who had rotavirus also had EPEC in stool culture. None of the other 9 had any pathogenic bacteria.

Virus particles other than rotavirus were seen in the stools of 10 children; adenovirus in 2, both of 
whom also had EPEC; enterovirus in 1, in whom no other cause was found for the diarrhoea, and coronavirus-like particles in 7 (Mathan et al., 1975).

Progress. 40 children required intraveneous fluids for 24-72 hours. After receiving oral electrolyte solution for $\mathbf{4 8}$ hours, the majority tolerated milk formula. However, 4 patients developed symptoms of secondary lactase deficiency with increased acidity and reducing substances in the stools when milk feeds were started. They responded well to lactosefree feeds. 41 children recovered within 5 days of admission. In 9, whose stools grew Salmonella (4), Shigella (3), Pseudomonas (1), and Klebsiella (1), the illness was more protracted. The child with marasmic kwashiorkor who had Pseudomonas in his stools, developed bronchopneumonia and died on the 14th hospital day; all the others recovered.

\section{Controls.}

Clinical features. The dietary history of the controls was similar to that of the patients. As judged by weight for age (Lancet, 1970), 20 were adequately nourished, 8 were undernourished, and 2 were marasmic. Microscopical examination of the stools showed no parasites.

Bacteriology. 6 of the children ( 2 aged $<6$ months, 3 from 7-12 months, and $1>12$ months) had EPEC in their stools. Their serotypes were among those isolated from the patients.

Virology. No rotavirus particles were detected in any of the controls, but enterovirus particles were found in 3 and coronavirus-like particles in 5 .

\section{Discussion}

Among the control children, 6 had EPEC in their stools but no diarrhoea. The presence of EPEC in apparently healthy children has been well documented, previous studies having shown that $8-12 \%$ of apparently healthy children of this age group excrete EPEC (Feldman et al., 1970). Rotavirus was not found.

Recognized bacterial pathogens were found in $66 \%$ of the 50 children studied. A number of factors may have contributed to this high isolation rate, including the method of selection of cases and the special attention given to the collection and processing of specimens. The stools from which Pseudomonas and Klebsiella were isolated provided pure cultures of these organisms, and in each case the organisms were also recovered in large numbers from the jejunal secretions. These organisms were probably responsible for the diarrhoea in these children. The pathogenicity of the Providence group of organisms has been in doubt, but there is evidence that at times they may produce gastroenteritis (Bhat et al., 1971b). In the child from whom this organism was recovered, the stool provided an almost pure culture of Providence and it is therefore likely that it caused the gastroenteritis. Thus, probable bacterial pathogens were isolated in $68 \%$ of the children.

As expected, because of the age group under study and the fact that children who passed blood and mucus were excluded, the commonest bacterial pathogens found were pathogenic $E$. coli. These were diagnosed by the use of 10 standard antisera. The serotypes $\mathrm{O} 21, \mathrm{O} 51$, and $\mathrm{O} 153$ were identified by Dr. Rowe. In our study the $E$. coli isolates were identified by serotyping; their enteropathogenicity therefore remains in doubt, particularly as Echeverria et al. (1976) have reported a lack of correlation between serotypes and enteropathogenicity. Screening of the isolates for their ability to produce enterotoxin and invade tissue is required to establish enteropathogenicity. However, there are reports that serotypes clearly implicated in outbreaks of diarrhoea were negative for toxin production using standard models (Gross et al., 1976). In our study the $E$. coli serotypes were the most predominant flora in the stool and were cultured in the majority of patients in the absence of rotavirus particles. In the control children the rate of isolation of enteropathogenic $E$. coli was low and the organisms were not the predominant flora in the stool. The $E$. coli serotypes isolated from the patients were therefore considered to be pathologically significant. The finding of rotaviruses in $26 \%$ of the cases confirms the preliminary report from this institution (Holmes et al., 1974) of the occurrence of this virus in children with gastroenteritis in India. All specimens in which rotavirus was found were obtained in the period July to December, and none during April to June when the environmental temperature is highest. Owing to circumstances beyond our control the study could not be conducted for the period January to March. An increase in the incidence of rotavirus infection in the winter months has been found by Bishop et al. (1973) and Albrey and Murphy (1976). The reasons for this seasonal variation are not clear but are presumably related to the way the infection is spread.

At the time of admission there was no difference in the clinical presentation of the children in whom rotavirus was found, those in whom bacterial pathogens were isolated, and those in whom no cause for the diarrhoea could be determined. The children with rotavirus recovered as quickly with 
appropriate rehydration therapy as those excreting EPEC. It is of interest that children in whom pathogenic bacteria other than EPEC were found had a more protracted illness.

Although the numbers studied were small, if the proportion of cases of gastroenteritis in childhood caused by rotavirus is extrapolated on a national scale, approximately one-quarter of the reported 1.4 million deaths per year in infants and children in India (India, Registrar General and Census Commissioner, 1972) are presumably due to a rotavirus infection, therefore making it a public health problem of considerable magnitude.

The authors are grateful to Dr. B. Rowe, Salmonella and Shigella Reference Laboratory, Colindale, London for serotyping some of the $E$. coli isolates.

\section{References}

Albrey, M. B., and Murphy, A. M. (1976). Rotaviruses and acute gastroenteritis of infants and children. Medical Journal of Australia, 1, 82-85.

Asakawa, Y., Akahane, S., Kagata, N., Noguchi, M., Sakazaki, R., and Tamura, K. (1973). Two community outbreaks of human infection with Yersinia enterocolitica. Journal of Hygiene, 71, 715-723.

Bhat, P., and Rajan, D. (1975). Comparative evaluation of desoxycholate citrate medium and xylose lysine desoxycholate medium in the isolation of shigellae. American Journal of Clinical Pathology, 64, 399-404.

Bhat, P., Myers, R. M., and Jadhav, M. (1971a). Shigellaassociated diarrhoeal disease in preschool children. Journal of Tropical Medicine and Hygiene, 74, 128-132.

Bhat, P., Myers, R. M., and Feldman, R. A. (1971b). Providence group of organisms in the aetiology of juvenile diarrhoea. Indian Journal of Medical Research, 59, 1010 1018.

Bhat, P., Shanthakumari, S., and Rajan, D. (1974). The characterisation and significance of Plesiomonas shigelloides and Aeromonas hydrophilia isolated from an epidemic of diarrhoea. Indian Journal of Medical Research, 62, 1051-1060.

Bishop, R. F., Davidson, G. P., Holmes, I. H., and Ruck, B. J. (1973). Virus particles in epithelial cells of duodenal mucosa from children with acute non-bacterial gastroenteritis. Lancet, 2, 1281-1283.

Bishop, R. F., Davidson, G. P., Holmes, I. H., and Ruck, B. J. (1974). Detection of a new virus by electron microscopy of faecal extracts from children with acute gastroenteritis. Lancet, 2, 149-151.

Cramblet, H. J., and Siewers, C. M. F. (1965), The etiology of gastroenteritis in infants and children with emphasis on the occurrence of simultaneous mixed viral-bacterial infections. Pediatrics, 35, 885-898.
Echeverria, P. D., Chang, C. P., and Smith, D. (1976). Enterotoxigenicity and invasive capacity of 'enteropathogenic' serotypes of Escherichia coli. Journal of Pediatrics, 89, 8-10.

Feldman, R. A., Bhat, P., and Kamath, K. R. (1970). Infection and disease in a group of south Indian families. IV. Bacteriologic methods and a report of the frequency of enteric bacterial infection in preschool children. American Journal of Epidemiology, 92, 367-375.

Flewett, T. H., Bryden, A. S., and Davies, H. (1974). Diagnostic electron microscopy of the faeces. I. The viral flora of the faeces as seen by electron microscopy. Journal of Clinical Pathology, 27, 603-614.

Gross, R. J.. Scotland, S. M., and Rowe, B. (1976). Enterotoxin testing of Escherichia coli causing epidemic infantile enteritis in the U.K. Lancet, 1, 629-631.

Holmes, I. H., Mathan, M., Bhat, P., Albert, M. J., Swaminathan, S. P., Maiya, P. P., Pereira, S. M., and Baker, S. J. (1974). Orbiviruses and gastroenteritis. Lancet 2, 658-659.

India, Registrar General and Census Commissioner (1972). Pocket Book of Population Statistics. Government Printing Office, New Delhi.

Jadhav, M. (1965). Report of Work Done on an Investigation of Diarrhoea in Infants and Children at Christian Medical College, Vallore. Indian Council of Medical Research, New Delhi.

James, J. W. (1972). Longitudinal study of the morbidity of diarrheal and respiratory infections in malnourished children. American Journal of Clinical Nutrition, 25, 690694.

Kamath, K. R., Feldman, R. A., Sundar Rao, P.S.S., and Webb, J. K. G. (1969). Infection and disease in a group of south Indian families. II. General morbidity patterns in families and family members. American Journal of Epidemiology, 89, 375-383.

Lancet, (1970). (Editorial.) Classification of malnutrition, 2, 302-303.

LeClair, R. A., Zen-Yoji, H., and Sakar, S. (1970). Isolation and identification of Vibrio parahaemolyticus from clinical specimens. Journal of the Conference of Public Health Laboratory Directors, 28, 82-92.

Mathan, M., Mathan, V. I., Swaminathan, S. P., Yesudoss, S., and Baker, S. J. (1975). Pleomorphic virus-like particles in human faeces. Lancet, 1, 1068-1069.

Moffet, H. L., Shulenberger, H. K., and Burkholder, E. R. (1968). Epidemiology and etiology of severe infantile diarrhea. Journal of Pediatrics, 72, 1-14.

Orskov, F., Orskov, I., Jann, B., and Jann, K. (1971). Immunoelectrophoretic patterns of extracts from all Escherichia coli $\mathbf{O}$ and $\mathrm{K}$ antigen test strains correlation with pathogenicity. Acta Pathologica et Microbiologica Scandinavica, Section B, 79, 142-152.

Prakash, O., Prakash, C. V., Amma, E., and Kalra, S. L. (1963). Microbial flora in cases of infantile diarrhoea in Delhi. Indian Journal of Medical Sciences, 17, 486-490.

Correspondence to Prof. S. M. Pereira, Department of Child Health, Christian Medical College and Hospital, Ida Scudder Road, P.O. Box No. 3, Vellore 630024, Tamil Nadu, India. 